Check for updates

Cite this: RSC Adv., 2018, 8, 39127

Received 30th August 2018

Accepted 10th November 2018

DOI: $10.1039 / c 8 \mathrm{ra07243d}$

rsc.li/rsc-advances

\section{Non-isothermal crystallization kinetics of polypropylene/short glass fibre/multiwalled carbon nanotube composites $\uparrow$}

\begin{abstract}
Nanoth Rasana, (D) a Karingamanna Jayanarayanan (D) *ab and Alessandro Pegoretti (D) ${ }^{\mathrm{c}}$
The non-isothermal crystallization kinetics of polypropylene (PP) reinforced with multiwalled carbon nanotubes (MWCNTs) and short glass fibres (GF) was studied by differential scanning calorimetry (DSC). The glass fibre concentration was maintained at $20 \mathrm{wt} \%$ and the MWCNT content ranged from 1 to $5 \mathrm{wt} \%$ in the PP matrix. The crystallization studies performed by DSC showed an increase in crystallization rate and a decrease in half time of crystallization of PP in the presence of micro and nano fillers. The Avrami, Ozawa, and Mo models were applied to analyze the non-isothermal crystallization behavior of PP multiscale composites. The Avrami model could very well describe the crystallization behavior of PP to $70 \%$ of the completion of crystallization. Beyond that level, it deviated significantly for all composites. On the other hand, the kinetics of crystallization could be well described by the Mo model. The strongest nucleating effect and the lowest activation energy were obtained for the composite with 2 wt\% MWCNT and 20 wt\% glass fibre. The X-ray diffraction analysis showed a significant reduction in the average crystal size in accordance with the amount of MWCNTs added.
\end{abstract}

\section{Introduction}

Polypropylene (PP) is a commonly used thermoplastic material which has applicability in household, commercial and industrial sectors with favourable cost/performance ratio. ${ }^{\mathbf{1}}$ The non-isothermal crystallization kinetics of polymer composites has captured wide attention since most of the polymer processing techniques are carried out under nonisothermal conditions. ${ }^{2,3}$ The selection of fillers to reinforce PP and control the mechanical and thermal properties of the resulting composite is crucial for technologists. The reinforcing fillers in PP influence the crystallization of (monoclinic, $\alpha$ ), (hexagonal, $\beta$ ), (triclinic, $\Upsilon$ ) crystalline forms and the size and distribution of spherulites. ${ }^{1}$ Being a nano filler, multiwalled carbon nanotubes (MWCNTs) exhibit considerable reinforcing potential and they act as excellent nucleating agents when incorporated in the polymer matrices.,5 Additionally, the inclusion of microscale glass fibre along with MWCNT in PP promotes heterogeneous nucleating effect and

${ }^{a}$ Department of Chemical Engineering and Materials Science, Amrita School of Engineering, Amrita Vishwa Vidyapeetham, Coimbatore, India

${ }^{b}$ Centre of Excellence in Advanced Materials and Green Technologies (CoE-AMGT), Amrita School of Engineering, Amrita Vishwa Vidyapeetham, Coimbatore, India. E-mail: kj_narayanan@cb.amrita.edu; kjnarayanan@gmail.com; Fax: +91-4222686274; Tel: +91-422-2685000

${ }^{c}$ Department of Industrial Engineering, University of Trento, Via Sommarive 9, 38123 Trento, Italy

† Electronic supplementary information (ESI) available. See DOI: 10.1039/c8ra07243d transcrystallization of PP chains surrounding the fillers. ${ }^{6,7}$ The properties of polymer matrices can be tailored significantly by the inclusion of micro, nano reinforcements. Besides, the physical, chemical and mechanical properties of polymer composites largely depend on the dispersion and distribution of fillers in the matrix, the degree of crystallinity and crystallite orientation and size.

Valerio-Cárdenas et $a l .{ }^{1}$ reported the effect of polyaniline grafted short glass fibre (PAN-g-SGF) on the crystallization kinetics of isotactic PP (iPP) under non isothermal conditions. The PAN- $g$-SGF accelerated the rate of crystallization of iPP significantly. In another report ${ }^{8}$ the heterogeneous nucleating effect of hemp fibre was studied with the conclusion that fibres could not accelerate the crystallization of PP. The observed behaviour was explained by assuming a large number of nucleating sites in presence of $30 \mathrm{wt} \%$ hemp fibre which in turn hindered the PP macromolecular mobility and ultimately retarded the rate $^{9}$ of the enhancement of crystallization process. In another work, an increased nucleation density was observed in poly(butylene terephthalate) in presence of glass fibres which resulted in higher crystallization in the nucleation of PP $\alpha$ crystals with the addition of MWCNTs as reported by Seo et $a l .{ }^{5}$ It was also described that non isothermal crystallization rate increased up to $4 \mathrm{wt} \%$ of CNTs and nucleation efficiency decreased at higher CNT content in PP. The reason for the decline in crystallization rate beyond optimum filler content was related to filler aggregation phenomena which restricted the formation of heterogeneous nuclei. ${ }^{10}$ The accelerated crystallization rate of PBT based halloysite 
nanotube composites was discussed by Oburoğlu et al. ${ }^{\mathbf{1 1}}$ It was also reported that nucleation activity and the crystallization rate was strongest at an optimum content of $2 \mathrm{wt} \%$ of silicon nitride $\left(\mathrm{Si}_{3} \mathrm{~N}_{4}\right)$ nano particles in PP. ${ }^{12}$ The incorporation of polystyrene (PS) functionalized single-walled carbon nanotubes (SWCNTs) led to the change in mechanism of nucleation and crystal growth of syndiotactic PS (SPS) and this effect was prominent at low loading of fillers. ${ }^{13}$

Many researchers have investigated the crystallization capabilities of PP containing nano or micro fillers individually. The effect of synergistic inclusion of multi-scale (nano and micro) fillers on non isothermal crystallization kinetics is not widely reported. The combined effect of carbon black and glass fibre on the crystallization characteristics of polyamide 6,6 at various cooling rates was explored by Layachi et al. ${ }^{2}$ An enhanced crystallization rate was achieved with the incorporation of glass fibre and an additional effect was attributed due to the presence of carbon black. Another report ${ }^{\mathbf{1 4}}$ detailed the increase of crystallinity in presence of short carbon fibres (SCF) dispersed in ultra high molecular weight polyethylene (UHMWPE) matrix. On the other hand, the crystallinity content decreased under the combined addition of silicon dioxide $\left(\mathrm{SiO}_{2}\right)$ nano particles. The interaction between the polymer chains and $\mathrm{SiO}_{2}$ nano particles in UHMWPE/SCFs/SiO ${ }_{2}$ composites could not promote heterogeneous nucleation. ${ }^{\mathbf{1 4}}$

There are no specific reports on the non-isothermal crystallization kinetics of PP/MWCNT/short glass fibre multiscale filler reinforced composites. In this study, the non-isothermal crystallization kinetics of PP composites containing MWCNTs at varying percentages ( 1 to $5 \mathrm{wt} \%$ ) and fixed content of glass fibre is studied by DSC analysis. As the mechanical properties of composites are greatly influenced by the morphology and crystallization characteristics, the study of non-isothermal crystallization of $\mathrm{PP} / \mathrm{MWCNTs} / \mathrm{GF}$ composites is crucial to identify the optimal crystalline morphology. To realize the potential of MWCNTs in PP/GF micro composites we need to establish relationships from experimental data which explains crystallization behavior of the matrix. Various theoretical models like Avrami, Ozawa, Mo and Kissinger's models are being utilized to analyze the non isothermal crystallization kinetics at different cooling rates of PP composites. X-ray diffraction studies are carried out to examine the crystal structure of PP in the presence of nano and micro fillers.

\section{Experimental}

\subsection{Materials}

Polypropylene granules (H200MA, Reliance, Mumbai, India) with a melt flow index of $20 \mathrm{~g} / 10 \mathrm{~min}$ and melting temperature of $167.7^{\circ} \mathrm{C}$ was used as the base matrix for composite preparation. The multiwalled carbon nanotubes functionalized with $1.5 \mathrm{wt} \%$ of $-\mathrm{COOH}$ were provided by United Nanotech Innovations Pvt. Ltd (India) with a specific surface area of $210 \mathrm{~m}^{2} \mathrm{~g}^{-1}$, average length 10-20 microns, outer diameter $20-30 \mathrm{~nm}$ and purity higher than $97 \%$. Cylindrical glass fibres of length and diameter approximately $3 \mathrm{~mm}$ and $10 \mu \mathrm{m}$ respectively were used as the micro filler.

\subsection{Composite preparation}

Polypropylene and glass fibres were preheated in a hot air oven at a temperature of $80{ }^{\circ} \mathrm{C}$ for about $1 \mathrm{~h}$ before melt processing for the removal of moisture. A masterbatch of MWCNTs in PP (weight content of MWCNT in masterbatch being $12.5 \%$ ) was prepared in a laboratory internal mixer maintained at $200{ }^{\circ} \mathrm{C}$ and $100 \mathrm{rpm}$. It was then mixed with different proportions of PP and $20 \mathrm{wt} \%$ of glass fibre and the dry blend was extruded in a counter rotating twin screw extruder (screw diameter: $25 \mathrm{~mm}$ and $L / D$ ratio: $30: 1$ ).

The temperatures maintained at different zones of the barrel were $155,170,180,210$ and $220^{\circ} \mathrm{C}$ respectively from the feed to the die zone and a screw speed of $110 \mathrm{rpm}$ was set for all runs. The extrudate pulled out of the die was quenched in a water bath at the exit of the extruder and the strands were then pelletized in a laboratory grinder. The control PP was also processed via melt mixing in twin screw extruder at the same temperature conditions from feed zone to die zone and set at the same screw speed as that for other composites.

The composites were named as PP, PPC1, PPC3, PPC5, PPG, PPGC1, PPGC2, PPGC3, PPGC5 with respect to the weight percentage of each component in the composite as described in Table 1.

All extruded strands were injection moulded in a Ferromatik Milacron-Sigma 50T injection moulding machine to prepare standard test specimens. Mould temperature was set as $60{ }^{\circ} \mathrm{C}$ and the processing temperature was set in the range of $190-210{ }^{\circ} \mathrm{C}$.

\section{Characterization methods}

\subsection{Scanning electron microscopy}

The morphology of the composites was analyzed using JEOL JSM-6490LA scanning electron microscope (SEM). The sample surfaces were immersed in hot xylene maintained at a temperature of $80{ }^{\circ} \mathrm{C}$ for about 10 minutes to remove the outer layer of PP in order to reveal the filler dispersion. Prior to the SEM analysis, all samples were coated with a thin (thickness $3 \mathrm{~nm}$ ) palladium-gold layer. Moreover, the fracture surfaces of the composites failed after tensile tests were also analyzed.

Table 1 Nomenclature of PP, nano, micro and multiscale filler reinforced composites

\begin{tabular}{lcll}
\hline Material & PP (wt\%) & Glass fibre (wt\%) & MWCNT (wt\%) \\
\hline PP & 100 & 0 & 0 \\
PPC1 & 99 & 0 & 1 \\
PPC3 & 97 & 0 & 3 \\
PPC5 & 95 & 0 & 5 \\
PPG & 80 & 20 & 0 \\
PPGC1 & 79 & 20 & 1 \\
PPGC2 & 78 & 20 & 2 \\
PPGC3 & 77 & 20 & 3 \\
PPGC5 & 75 & 20 & 5
\end{tabular}




\subsection{Mechanical properties measurement}

Universal Tensile Testing Machine at a constant cross head speed of $50 \mathrm{~mm} \mathrm{~min}^{-1}$ was used to perform tensile tests. The tensile specimens are injection moulded dumbbell-shaped ASTM D638 specimens and all mechanical properties were measured at room temperature.

\subsection{Differential scanning calorimetry}

Differential scanning calorimetry (DSC) were performed by a TA Instruments Q20 V24.10 Build 122 make device under non isothermal conditions. The specimens selected from injection moulded samples were heated up to $200{ }^{\circ} \mathrm{C}$, retained there for five minutes in order to erase the unknown thermo mechanical history due to injection moulding. Subsequently, the samples were cooled down to room temperature at various cooling rates such as 5, 10, 15 and $20{ }^{\circ} \mathrm{C} \min ^{-1}$ and after crystallization the samples were again heated to $200{ }^{\circ} \mathrm{C}$. The first cooling curve parameters are used to study the crystallization kinetics of samples and the second heating DSC curves are used to identify the melting temperature $\left(T_{\mathrm{m}}\right)$. The relative crystallinity of the PP phase was also estimated using the exothermic heat data obtained during the cooling scan.

For non-isothermal crystallization process, Kissinger ${ }^{2}$ proposed that the activation energy for the crystallization process could be evaluated using the expression (1) that relates cooling rate $(R)$ and peak crystallization temperature $\left(T_{\mathrm{c}}\right)$.

$$
\frac{\mathrm{d}\left(\ln \left(\frac{R}{T_{\mathrm{c}}^{2}}\right)\right)}{\mathrm{d}\left(\frac{1}{T_{\mathrm{c}}}\right)}=-\frac{\Delta E}{R_{\mathrm{u}}}
$$

where ' $R_{\mathrm{u}}$ ' is the universal gas constant, 'R' is cooling rate and ' $\Delta E$ ' is the activation energy at different cooling rates. Integrating expression (1), final expression (2) to estimate activation energy is obtained.

$$
\ln \left(\frac{R}{T_{\mathrm{c}}^{2}}\right)=\frac{1}{T_{\mathrm{c}}}\left(-\frac{\Delta E}{R_{\mathrm{u}}}\right)
$$

The slope of the plot of $\ln \left(\frac{R}{{T_{\mathrm{c}}}^{2}}\right) v s$. $\left(\frac{1}{T_{\mathrm{c}}}\right)$ gives $\frac{\Delta E}{R_{\mathrm{u}}}$ from which activation energy could be calculated.

The parameter named nucleation activity $(\phi)$ explains the nucleating ability in the presence of fillers in the polymer melt. ${ }^{15}$ The value of nucleation activity ranges from 0 to 1 and lower ' $\phi$ ' value indicates stronger nucleant effect. In accordance with Dobreva and Gutzow ${ }^{\mathbf{1 6}, 17}$ the activity of nucleating agent in polymer melts could be estimated as $\phi=\frac{B^{*}}{B}$ while $B^{*}$ and $B$ are the parameters representing homogeneous and heterogeneous nucleation, respectively. The nucleation activity was estimated from the slope of the following equation. ${ }^{3}$

$$
\ln R=\text { const }-\frac{B}{\Delta T_{P}^{2}}
$$

where $\Delta T_{\mathrm{p}}$ is the temperature difference between melting $\left(T_{\mathrm{m}}\right)$ and peak crystallization temperature $\left(T_{\mathrm{c}}\right)$.

\subsection{X-ray diffraction analysis}

The crystal structure of PP, PPG and PPGC composites were analyzed by a wide angle X-ray diffractometer - Rigaku Ultima IV with X-ray source of $\mathrm{Cu}$, operated at $40 \mathrm{kV} / 40 \mathrm{~mA}$ at continuous scanning mode of $2 \theta$ from 10 to $90^{\circ}$ with steps of $0.02^{\circ}$. The XRD analysis was performed on compression moulded films. In particular, the injection moulded samples were compression moulded in the hot press at $200{ }^{\circ} \mathrm{C}$ under a pressure of $4 \mathrm{MPa}$ for $150 \mathrm{~s}$ between Teflon sheets. The moulded films were then cooled to room temperature by water circulation at a cooling rate of about $20^{\circ} \mathrm{C} \mathrm{min}^{-1}$.

\section{Results and discussion}

\subsection{Microstructure analysis}

Fig. 1(a) represents the uniform dispersion of glass fibres in PP matrix (the SEM image refers to the fracture surface of tensile specimen of PPG composite) and Fig. 1(b) shows the fractured surface of tensile specimen which delineates the dispersion of glass fibres in the PP matrix. Fig. 1(c) and (d) represent the dispersion and distribution of MWCNTs in nano (PPC3) and multiscale filler reinforced (PPGC3) composites. The intertwined and entangled network of MWCNTs (Fig. 1(e)) provides a strong interface between the glass fibre and the polypropylene matrix which in turn improves the interfacial shear strength. Fig. 1(f) indicates the presence of well dispersed CNTs on the glass fibre.

Once the nano and micro scale fillers are incorporated in PP matrix, due to high aspect ratio of MWCNTs available in the neighbourhood of glass fibres have a tendency to wrap around glass fibres develop mechanical interlocking and hold them firm within the matrix. Also PP chains can form complex entanglement around nanotubes and upon loading PP chains could stretch to its maximum and undergoes yielding. The effective surface area to volume ratio is high for nanotubes and hence PP chains could adhere and entangle more on nano scale CNTs than on micro scale glass fibre. The morphology attained could enhance the crystallization properties which in turn improves the overall mechanical properties of the composites.

\subsection{Mechanical properties}

As shown in Table S1 $\uparrow$ neat PP exhibits a tensile strength of $29 \mathrm{MPa}$. The inclusion of nano filler (content of 1, 3 and $5 \mathrm{wt} \%$ ) alone in PP matrix could not improve the tensile strength and modulus to a greater extent. In addition the incorporation of $20 \mathrm{wt} \%$ of glass fibres in PP matrix has significantly improved the tensile strength by $43.5 \%$ and the Young's modulus of the composite has improved by $131 \%$. The lowest value of strain at break (\%) indicates the brittle characteristics of PPG composite while PPC composites show a more ductile behavior.

The stress strain plots of neat PP, PPC, PPG and PPGC composites are shown in Fig. 2. 

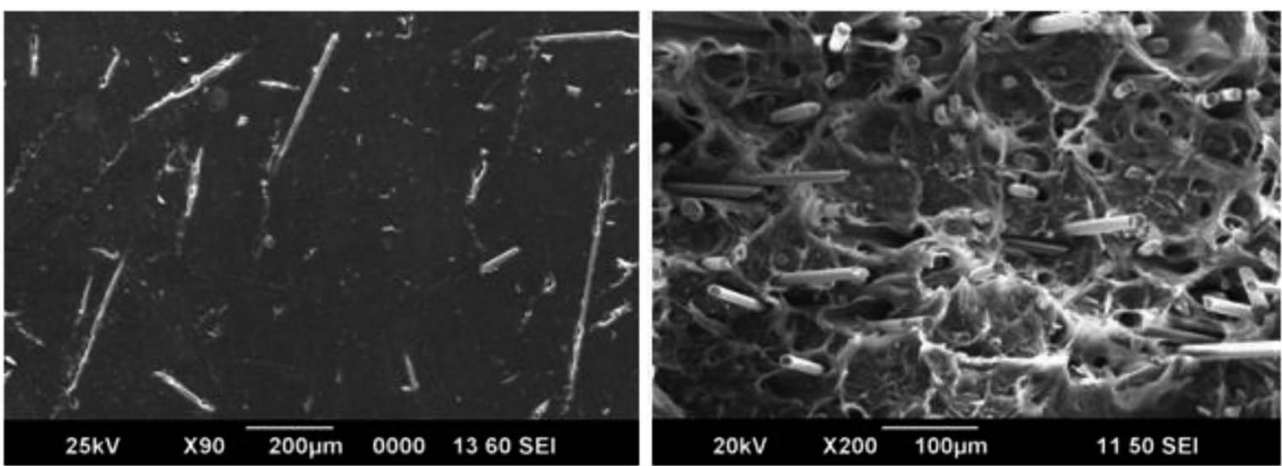

(a)

(b)
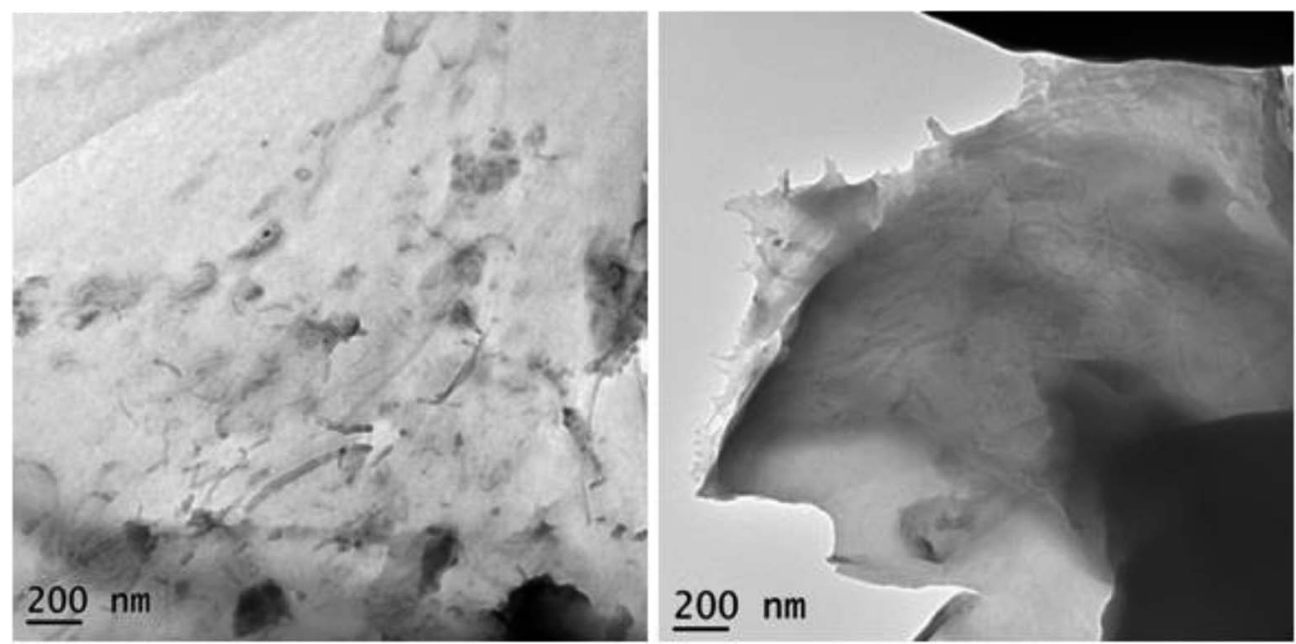

(c)

(d)
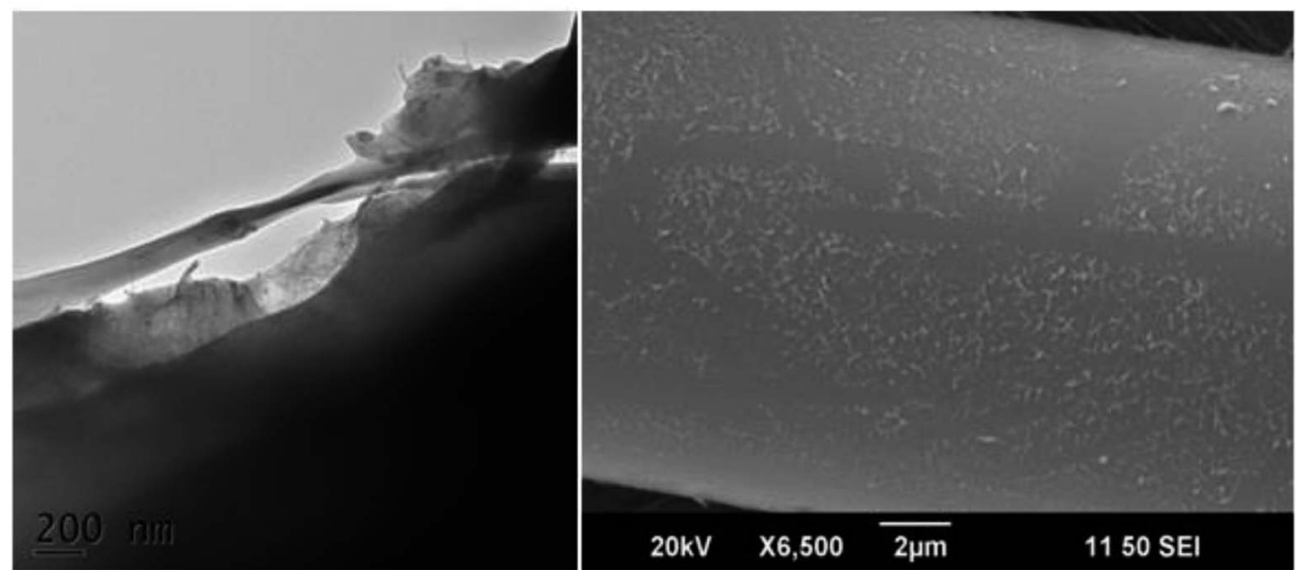

(e)

(f)

Fig. 1 ( $a$ and b) SEM micrographs of PPG micro composite indicate the uniform dispersion of glass fibres in PP matrix (c) TEM micrograph of the tensile fracture surface of a nanocomposite showing the dispersion of 3 wt\% of MWCNTs in PP matrix. (d) TEM micrograph showing the dispersion of MWCNTs in PPGC3 composite. (e) TEM image showing the entangled network of MWCNTs at the edges of glass fibre in PPGC3 composite (f) SEM image of an enlarged glass fibre in PPGC3 composite indicating the dispersion of MWCNTs on the surface and on the edges of glass fibre.

The addition of $3 \mathrm{wt} \%$ of carbon nanotubes in PPGC3 composite has raised the tensile strength by $76 \%$ with respect to neat PP and enhanced the modulus by $127 \%$. The incorporation of MWCNTs in PPG composite has improved the strain\% values at break which shows the semi ductile behavior of PPGC composites in comparison with PPG micro composite. This is due to the fact that the extremely flexible PP chains could wrap around CNTs and stretch to its maximum. The increase in elongation at break for PPGC composites is a testimony for this inference. 


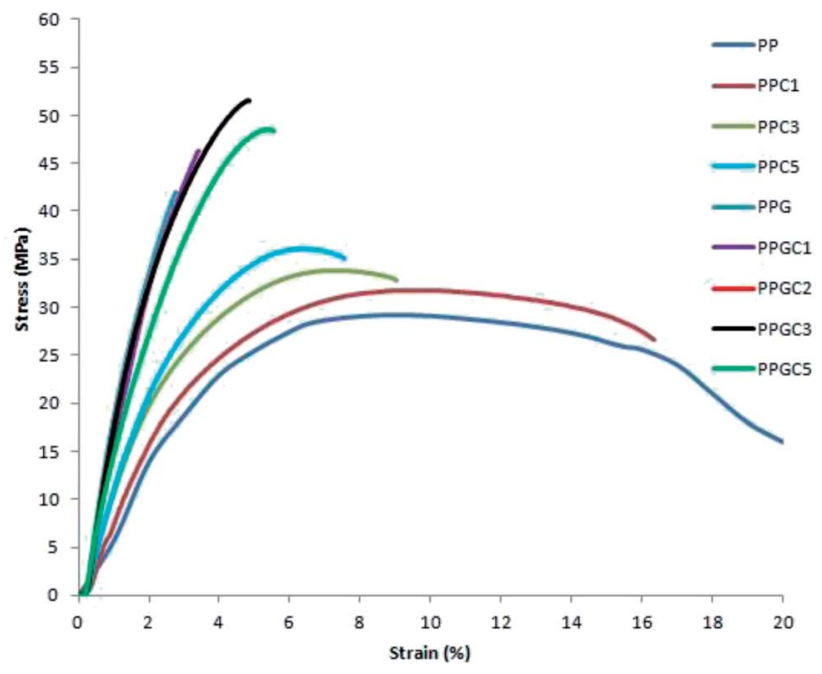

Fig. 2 Stress strain plots of neat PP, PPC, PPG and PPGC composites.

\subsection{Non-isothermal crystallization}

The non-isothermal crystallization exotherms of neat PP, PPG and PPGC composites at different cooling rates are shown in Fig. S1. $\dagger$ The onset and endset temperatures $\left(T_{\mathrm{o}}\right.$ and $\left.T_{\mathrm{e}}\right)$, peak crystallization temperature $\left(T_{\mathrm{c}}\right)$, crystallization half time $\left(t_{1 / 2}\right)$, and half width of crystallization peaks $(\Delta w)$ obtained from DSC cooling curves are summarized in Table S2. $\dagger$ The melting temperature $\left(T_{\mathrm{m}}\right)$ is obtained from the second heating curves of thermal cycle in DSC analysis.

The relative crystallinity of polymer matrix as a function of temperature $\left(X_{\mathrm{c}}(T)\right)$ and time $\left(X_{\mathrm{c}}(t)\right)$ at different cooling rates under non isothermal conditions could be estimated as reported in the following equations., ${ }^{2,12,18}$

$$
\begin{gathered}
X_{\mathrm{c}}(T)=\frac{\int_{T_{\mathrm{o}}}^{T} \frac{\mathrm{d} H}{\mathrm{~d} T} \mathrm{~d} T}{\int_{T_{\mathrm{o}}}^{T_{\mathrm{e}}} \frac{\mathrm{d} H}{\mathrm{~d} T} \mathrm{~d} T} \\
X_{\mathrm{c}}(t)=\frac{\int_{t_{\mathrm{o}}}^{t} \frac{\mathrm{d} H}{\mathrm{~d} t} \mathrm{~d} t}{\int_{t_{\mathrm{o}}}^{t_{\mathrm{o}}} \frac{\mathrm{d} H}{\mathrm{~d} t} \mathrm{~d} t}
\end{gathered}
$$

where ' $H$ ' is heat flow, $t_{\mathrm{o}}$ and $t_{\mathrm{e}}$ are start and end of crystallization time respectively.

The absolute crystallinity of the polymer matrix in a blend or composite can be determined by the following equation. ${ }^{19,20}$

$$
X_{\mathrm{c}}=\left(\frac{\Delta H_{\mathrm{f}}}{\Delta H_{\mathrm{f}}^{0} \times w}\right) \times 100
$$

where $\Delta H_{\mathrm{f}}$ is the enthalpy of fusion, $\Delta H_{\mathrm{f}}^{0}$ is the enthalpy of fusion of pure crystalline PP $\left(207 \mathrm{~J} \mathrm{~g}^{-1}\right){ }^{19}$ ' $w$ ' is weight fraction of polymer in the composite.

From the values listed in Table $\mathrm{S} 2 \uparrow$ it can be observed that the onset of crystallization and peak crystallization temperatures decrease with increasing cooling rate. The two prime factors affecting the crystallization of filler incorporated composites are (i) the restrictions of segmental polymer chain mobility and (ii) heterogeneous nucleation. The decrease in the mobility of polymer chains could impede the formation of a perfect crystalline structure and it reduces $T_{\mathrm{c}}$ values. As the cooling rate increases, nucleation occurs at relatively lower temperatures and the number of nucleating sites also reduces. It is widely agreed that the heterogeneous nucleation could accelerate the motion of polymer chains and a consequent rise in $T_{\mathrm{c}}{ }^{14,21,22}$ The crystalline spherulites formed at lower temperatures possess more defects and are smaller in size and in turn leads to reduction in melting temperature $\left(T_{\mathrm{m}}\right)$. Depending upon the predominant factor (hindered mobility of polymer chains vs. heterogeneous nucleation) the crystallization behavior could be predicted.

At all the cooling rates both $T_{\mathrm{o}}$ and $T_{\mathrm{c}}$ values increase with the addition of glass fibres in neat PP. This reveals that the glass fibres act as nucleating sites and the nucleation and progression of crystallization occurs at higher temperatures which could lead to an increase in absolute crystallinity. The addition of MWCNTs in PPG composite further improved the onset and peak crystallization temperature which explains the synergetic effect of multiscale fillers in promoting heterogeneous nucleation. The addition of MWCNTs provided large number of nucleation sites and promoted chain mobility resulting in increased $T_{\mathrm{c}}$. Hence $T_{\mathrm{c}}$ for all PPGC composites have shifted to higher temperatures with increase in MWCNT content. Beyond $2 \mathrm{wt} \%$ of MWCNT, there is a slight drop in $T_{\mathrm{c}}$ of composites and this could be due to agglomeration of MWCNTs in the matrix at higher loading.

The variation of relative crystallinity of PP phase in the samples with respect to temperature and time at different cooling rates are shown in Fig. S2 and S3. $\dagger$ All curves in Fig. S2 and $\mathrm{S} 3 \dagger$ presents a characteristic S-shape which delineates initial slow rate of nucleation, followed by fast rate of nuclei growth. In the next stage the growth of the crystals are retarded by spherulites impingement. ${ }^{14}$ The values of $t_{1 / 2}$ for PPG and PPGC composites are lower than that of virgin PP and this describes the enhanced crystallization rate of PP in the composites when compared to neat PP. At the same cooling rate the value of $t_{1 / 2}$ is lower for PPGC2 composite with regard to neat PP. The sharpness of peaks of crystallization indicated by ' $\Delta w$ ' value is higher for PPGC1 and PPGC2 composite in comparison with PP which further describes the faster crystallization rate of PPGC composites.

As shown in Fig. $\mathrm{S} 2 \uparrow$ at higher cooling rates the curves shift to lower temperatures which indicate an insufficient time for the polymer chains to rearrange themselves during crystallization. Similarly, at higher cooling rates (Fig. S3 $\dagger$ ) the decrement in crystallization time is related to the short time period available for the lamellas for an ordered arrangement, which ultimately leads to imperfect crystal formation..$^{14,21,22}$

In order to analyze the crystallization process induced by the incorporation of CNTs alone in the PP matrix, the thermal properties obtained from the DSC analysis for neat PP, PPC, PPG and PPGC composites at a single cooling rate (of $5{ }^{\circ} \mathrm{C} \min ^{-1}$ ) are reported in Table 2 . 
It could be noticed that the inclusion of $3 \mathrm{wt} \%$ of MWCNTs enhanced $T_{\mathrm{c}}$ (crystallization temperature) by $19^{\circ} \mathrm{C}$. The main reason is the excellent nucleating ability of MWCNTs in the matrix which causes the accelerated growth of spherulites. The drop in $T_{\mathrm{c}}$ beyond $3 \mathrm{wt} \%$ of nano fillers is due to the formation of nano agglomerates. In comparison with microcomposite, nanocomposites show higher $T_{\mathrm{c}}$ values owing to the fact that the MWCNTs provided accelerated transcrystallization than glass fibres.

Among the PPGC composites, PPGC2 exhibits maximum $T_{\mathrm{c}}$ due to the synergistic nucleation offered by multiscale fillers. The ' $T_{\mathrm{o}}$ ' shifting to higher temperatures could be observed for PPGC composites than neat PP. A significant decrease in $T_{\mathrm{m}}-$ $T_{\mathrm{c}}$ values were exhibited by PPC 3 and PPGC2, which is suggestive of the accelerated crystallization process. The reduced $\Delta w$ value of PPC and PPGC composites represents uniform crystal size distribution. The slight decrease in melting temperatures of composites is due to the disturbance caused in the crystalline regions of PP with the incorporation of nano and micro fillers. ${ }^{23}$

As reported in Table 2, while nanocomposites are considered, the crystallization parameters are significantly improved with respect to neat PP. The presence of nano fillers alone in the matrix did not enhance tensile strength and modulus conspicuously. The positive effect of MWCNTs was an improvement in the ductility as evidenced in the case of PPC3 and PPC5 with regard to micro composite (PPG). In a larger perspective, the nano fillers are expensive and although they could impart some specific properties the agglomeration tendency prevails beyond $3 \mathrm{wt} \%$. On the other hand, glass fibres incorporated in PP matrix (PPG micro composite) are cost effective and improves the strength, stiffness and rigidity but at the cost of ductility and toughness. In multiscale composites the entanglement of nano fillers at the interface between micro scale fillers and matrix could greatly enhance the interfacial strength. The effective nano filler-micro filler network can trap polymer chains and thus segmental mobility of the chains is greatly reduced. In the applications where high modulus and strength is required catastrophic brittle fracture would be unacceptable. In such situations the synergy of micro and nano fillers has immense significance and they can coexist in polymer matrix to produce multiscale filler reinforced composites.

Table 2 Thermal properties of neat PP, PPC, PPG and PPGC composites at a cooling rate of $5^{\circ} \mathrm{C} \mathrm{min}^{-1}$

\begin{tabular}{lllllll}
\hline Sample & $T_{0}\left({ }^{\circ} \mathrm{C}\right)$ & $T_{\mathrm{c}}\left({ }^{\circ} \mathrm{C}\right)$ & $T_{\mathrm{e}}\left({ }^{\circ} \mathrm{C}\right)$ & $T_{\mathrm{m}}\left({ }^{\circ} \mathrm{C}\right)$ & $t_{1 / 2}(\mathrm{~min})$ & $\Delta w$ \\
\hline PP & 119.8 & 113.13 & 109.1 & 167.15 & 66 & 5 \\
PPC1 & 134.2 & 128.8 & 124.8 & 165.9 & 56.6 & 3.2 \\
PPC3 & 137.2 & 132.5 & 127.2 & 165.5 & 60 & 4.8 \\
PPC5 & 137.5 & 131.7 & 128 & 165.9 & 57.2 & 4.5 \\
PPG & 129.9 & 125.8 & 121.4 & 164.98 & 51.6 & 3.6 \\
PPGC1 & 133 & 127.02 & 123.2 & 165.3 & 59.34 & 3.5 \\
PPGC2 & 134.8 & 129.55 & 126.25 & 164.84 & 51.3 & 4 \\
PPGC3 & 133.8 & 128.6 & 125 & 166.04 & 52.92 & 4.2 \\
PPGC5 & 134.3 & 128.91 & 123.3 & 165.65 & 66.1 & 4.4
\end{tabular}

\subsection{The Avrami equation}

The classical Avrami equation is generally used to explain the primary stage of crystallization under isothermal conditions. It elucidates the variation in relative crystallinity of the polymer with crystallization time as presented in eqn (7)..$^{5,14,24}$

$$
1-X_{\mathrm{c}}(t)=\exp \left(Z t^{n}\right)
$$

where ' $Z$ ' is a crystallization rate constant, $X_{\mathrm{c}}(t)$ is the relative degree of crystallinity at time ' $t$ ' and ' $n$ ' is the Avrami exponent, which is influenced by type of nucleation and crystallite dimension. ${ }^{2,14}$ The logarithmic form of eqn (7) can be represented as:

$$
\log \left(-\ln \left(1-X_{\mathrm{c}}(t)\right)\right)=n \log t+\log Z
$$

In the plot of $\left(-\ln \left(1-X_{\mathrm{c}}(t)\right)\right)$ versus $\log t$, if the data follow a linear trend, ' $n$ ' represents the slope and $\log Z$ represents the intercept.

To extend the application of Avrami model to nonisothermal crystallization characteristics of polymers Jeziorny ${ }^{24}$ modified the model assuming that non isothermal crystallization is a synergy of infinitesimally small isothermal steps. The modified Avrami model can be represented by eqn (9) and crystallization rate constant $Z_{\mathrm{c}}$ could be evaluated.

$$
\log Z_{\mathrm{c}}=\frac{\log Z}{R}
$$

Fig. 3 shows Avrami plots of neat PP and composites at varying cooling rates. The curves are almost parallel to each other but they do not follow an exact linear relationship. However, the linearity obtained at the initial portion of crystallization curves are used to estimate Avrami and Jeziorny's kinetic constants and are presented in Table S3. $\dagger$

The increase in $Z_{\mathrm{c}}$ values with increasing cooling rates describes the higher crystallization rate. ${ }^{2}$ The average of Avrami exponents for virgin PP and PP composites were 1.62, 2.11, 2.32, $2.87,3.1$ and 2.73 respectively. Avrami exponent increases with the addition of glass fibre and MWCNTs and decreases at higher content of $5 \mathrm{wt} \%$ of CNTs. This explains that heterogeneous nucleation is promoted by the presence of multiscale fillers. ${ }^{25}$ The results show that MWCNTs have an important role in nucleating PP crystals under non-isothermal conditions. At low cooling rate of $5{ }^{\circ} \mathrm{C} \mathrm{min}{ }^{-1}$ crystallization rate increases up to $2 \mathrm{wt} \%$ of MWCNTs and a slight decrease in nucleation efficiency can be observed beyond that.

This decrease in the crystallization rate constant may not be due to change of crystallization mechanism like type of nucleation and geometry of crystal growth. This might be due to aggregation of nanotubes at higher concentrations which leads to a reduction in the number of heterogeneous nucleation sites. ${ }^{10}$ However, at higher cooling rates, the crystallization rate constant increases with the addition of fillers and then it decreases or remains almost constant even at higher filler content. At the same cooling rate, $Z_{\mathrm{c}}$ values of PPG and PPGC 
(a)

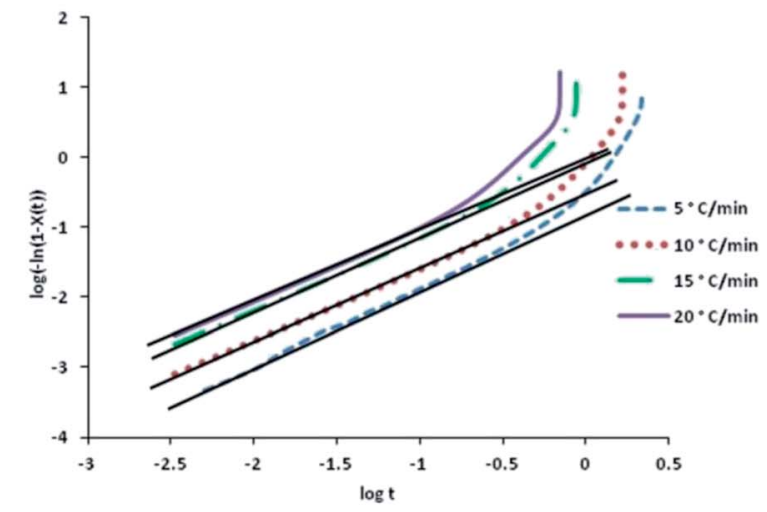

(c)

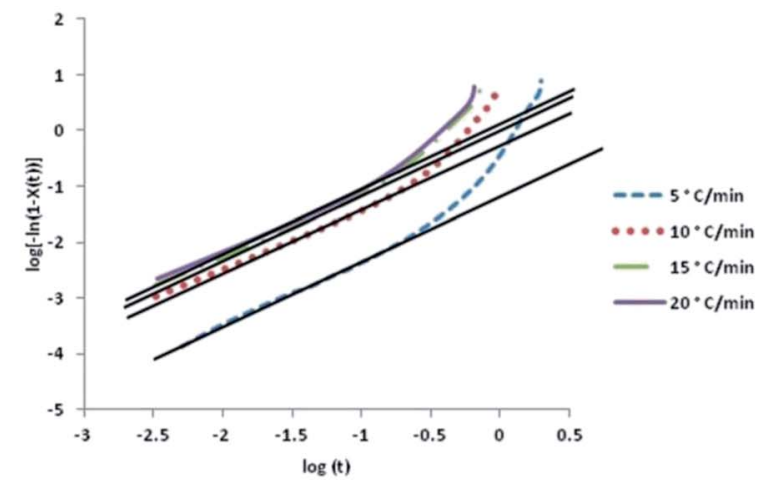

(e)

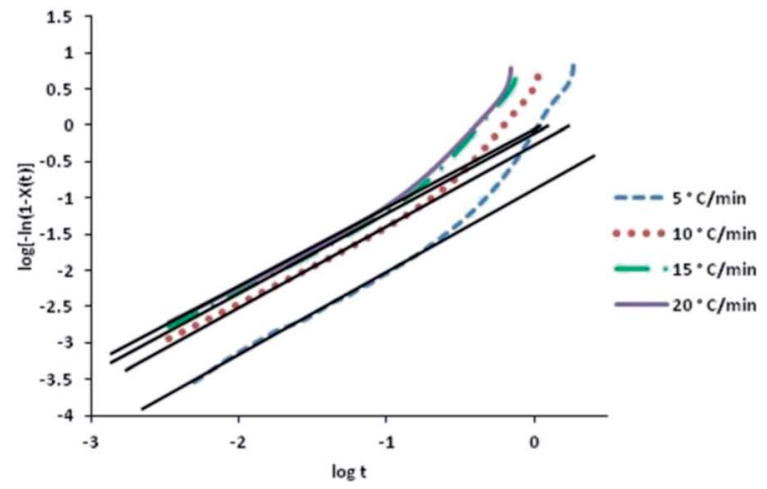

(b)

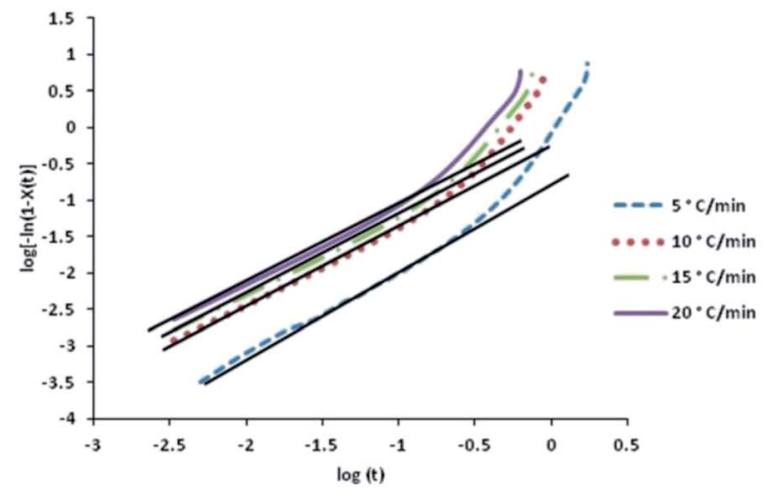

(d)

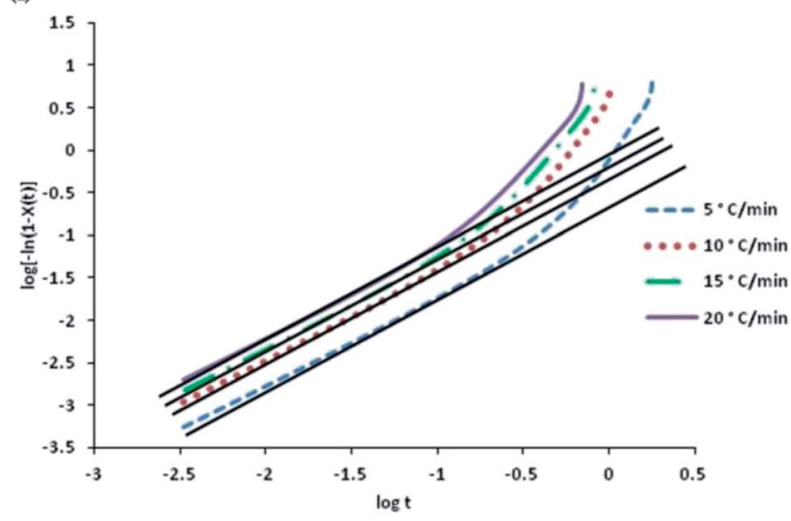

(i)

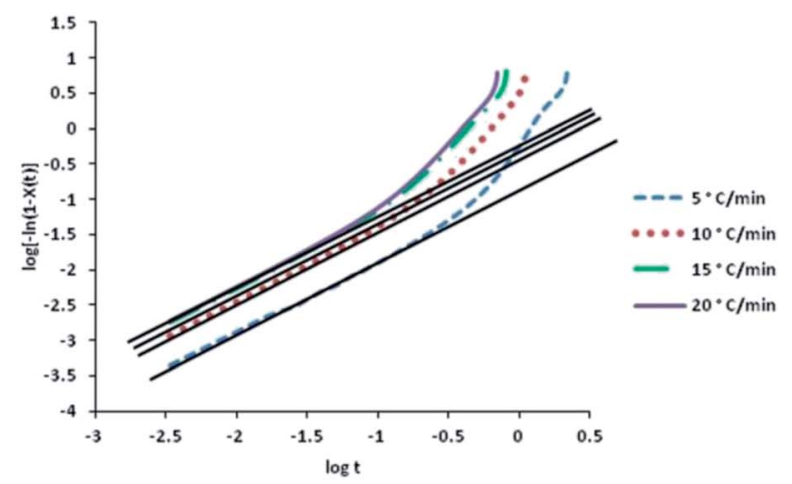

Fig. 3 Avrami plots of $\log [-\ln (1-X(t))]$ as a function of log $t$ at varying cooling rates for non isothermal crystallization (a) PP, (b) PPG, (c) PPGC1, (d) PPGC2, (e) PPGC3, (f) PPGC5.

composites are higher in comparison to neat PP which explains that crystallization rate constant was improved by the presence of glass fibres when added individually and also in combination with CNTs.

\subsection{Ozawa model}

The crystallization rate of polymers could also be estimated using the Ozawa model. According to this model the relative degree of crystallinity $X(T)$ at temperature ' $T$ ' for non-isothermal crystallization at constant cooling rate can be estimated as follows. ${ }^{2,3,14}$

$$
1-X(T)=\exp \left[\frac{-K(T)}{R^{m}}\right]
$$

The linearization of eqn (10) results in eqn (11)

$$
\log [-\ln (1-X(T))]=\log K(T)-m \log R
$$

where ' $K(T)$ ' is cooling crystallization function, ' $m$ ' is the Ozawa exponent which depends on the mechanism of nucleation and crystal growth dimension and ' $R$ ' is a cooling rate constant. The slope and intercept of Ozawa model represented by eqn (11) 
corresponds to the Ozawa exponent ' $m$ ' and $\log K(T)$ respectively.

Fig. 4 reports the Ozawa plots of $\log [-\ln (1-X(t)] v s . \log R$ at different temperatures between $T_{\mathrm{o}}$ and $T_{\mathrm{e}}$. Ozawa model could describe the crystallization behaviour if the plots of $\log [-\ln (1-$ $X(t)] v s . \log R$ exhibits linearity. ${ }^{8}$ It is observed from the plots that the presence of fillers changes the crystallization mechanism and linearity could not be observed in all curves. The curvature obtained in the plots relative to neat PP and PP composites suggests that Ozawa model is not suitable for describing the crystallization kinetics of the investigated materials.
In fact, the transcrystallization effect of PP chains around glass fibres and MWCNTs and the effect of secondary crystallization at the later stages of crystallization are not fully captured by the Ozawa model. At different temperatures between $T_{\mathrm{o}}$ and $T_{\mathrm{e}}$, the crystallization kinetics induced by glass fibres and MWCNTs could not exactly match the behavior predicted by Ozawa model. At a specified temperature between $T_{\mathrm{o}}$ and $T_{\mathrm{e}}$, the crystallization process at various cooling rates are at different stages and thus linearity is not followed. ${ }^{26}$ At temperatures close to the onset of crystallization, linearity is manifested whereas at the intermediate stages of crystallization, when rate of (a)

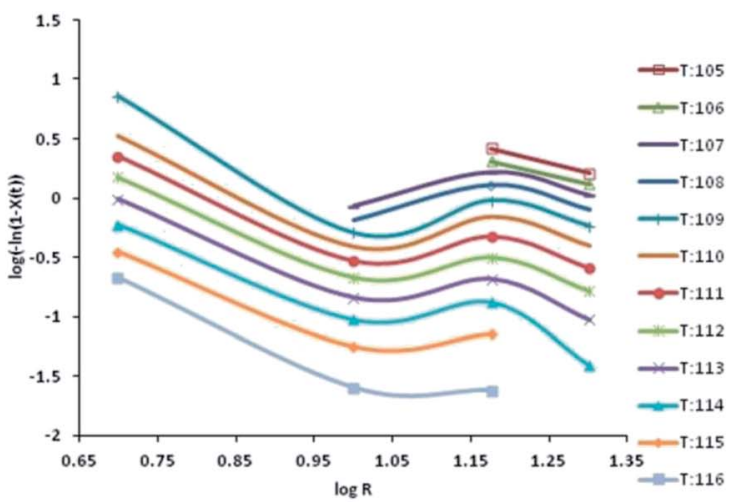

(c)

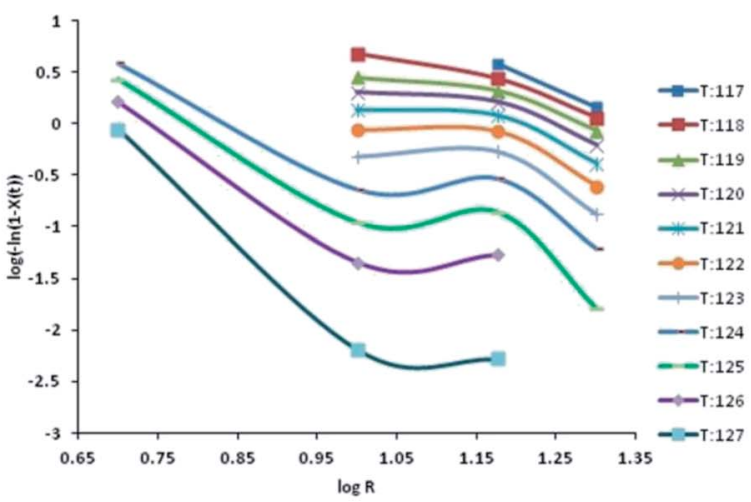

(b)

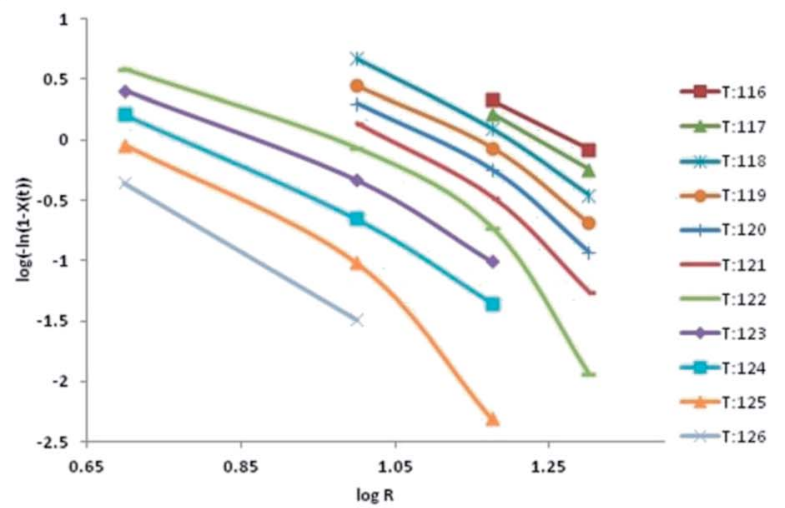

(d)
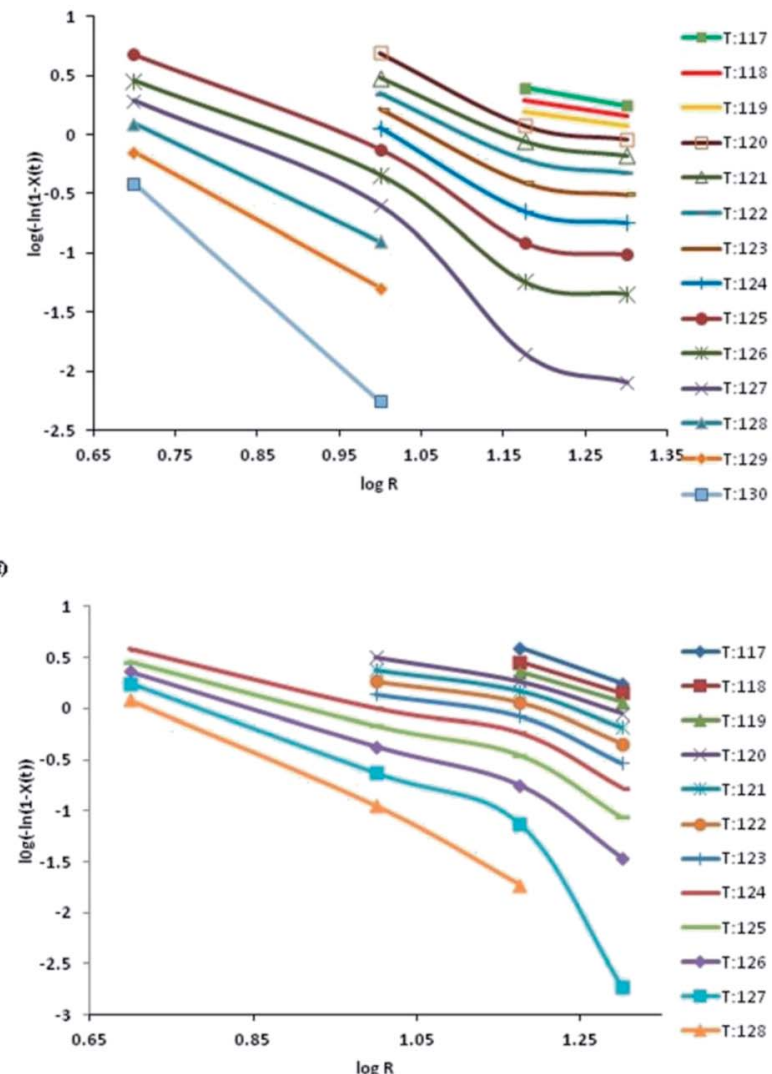

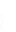

Fig. 4 Ozawa plots of $\log [-\ln (1-X(t)]$ as a function of $\log R$ for different temperatures for non-isothermal crystallization (a) PP, (b) PPG, (c) PPGC1, (d) PPGC2, (e) PPGC3 and (f) PPGC5.

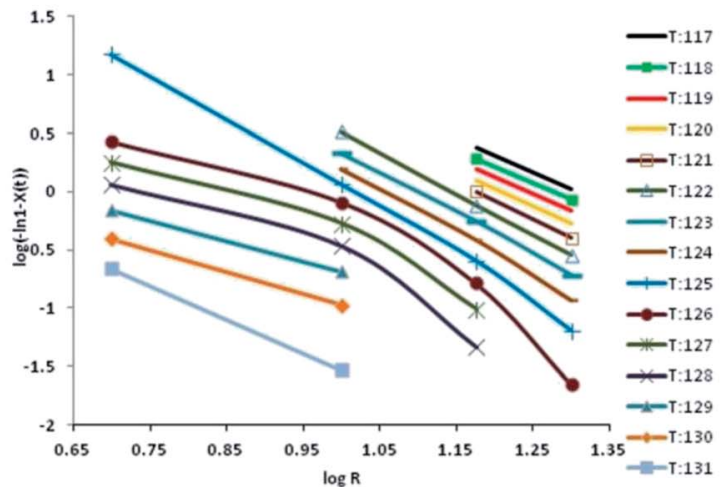


nucleation is high, deviation occurs from linearity. This witness the complexity in crystallization mechanism induced by the fillers.

\subsection{Mo's model}

By combining Ozawa and Avrami equations, Mo et al. ${ }^{27}$ suggested a model for explaining the non-isothermal crystallization kinetics.

$$
\begin{gathered}
\log Z+n \log t=\log (K(T))-m \log (R) \\
\log R=\log (F(T))-\alpha \log (t)
\end{gathered}
$$

where $F(T)=\left(\frac{K(T)}{Z}\right)^{1 / m}, \alpha=\frac{n}{m} F(T)$ refers to a value of the crystallization rate in cooling chosen at unit crystallization time at a specific degree of crystallinity and ' $\alpha$ ' is the ratio of Avrami to Ozawa exponent. ${ }^{14,28}$ The linearized model represented by eqn (13) gives the slope and intercept which corresponds to ' $\alpha$ ' and $\log F(T)$ respectively.

The non-isothermal crystallization kinetics of PP and MWCNT reinforced PP/glass fibre composites are accurately accounted by the Mo's model. It could be observed from Fig. 5 that for neat PP and PP composites a perfect linear relationship is obtained by plotting $\log R v s$. $\log t$. Table $S 4 \uparrow$ lists the kinetic parameters $F(T)$ and $\alpha$ obtained from the Mo's model. It is observed that $F(T)$ and $\alpha$ increases with increase in percentage relative crystallinity. The smaller values of $F(T)$ depicts higher crystallization rate demonstrating that the inclusion of glass fibres and MWCNTs accelerates the crystallization rate.

Experimental results show a good fitting with Mo's model confirmed by the higher $R^{2}$ values obtained from the linear plots of $\log R v s$. $\log t$. At a certain relative crystallinity a higher $F(T)$ value indicates the need of a higher cooling rate to reach that specific relative crystallinity in unit time which also explains the possibility of a complex crystallization process. ${ }^{11,29,30}$ Comparing the ' $\alpha$ ' values, neat PP exhibits lower values when compared to PP composites. Since $\alpha=n / \mathrm{m}$, the PP composites reinforced with both glass fibres possess higher ' $n$ ' values and consequently ' $\alpha$ ' values are higher for them. However, the observed decreased ' $\alpha$ ' values induced by the addition of MWCNTs explains the complexity of crystallization geometry of those composites. $^{21}$

\subsection{Activation energy}

Fig. S4 $\uparrow$ shows the Kissinger's plot for neat PP and composites and the slope of the plots are used to estimate activation energies. Li et $a l .{ }^{31}$ explained that the magnitude of activation energy is related to the energy that is required for the movement of polymer chains when transformed from the melt to the crystalline state. A higher value of $\Delta E$ is indicative of the higher release of energy occurring during cooling suggesting difficulties in the motion of polymer chains during crystallization. ${ }^{32}$ The activation energy obtained for PP, PPG and PPGC composites with MWCNTs varying between 1 to $5 \mathrm{wt} \%$ are 299, $322,325,344,331$ and $316 \mathrm{~kJ} \mathrm{~mol}^{-1}$ respectively. The $\Delta E$ of neat
PP is higher than that of PPG and PPGC composites which is an evidence of the difficulty in rearrangement of PP chains leading to lowest crystallization rate. On the other hand, due to the heterogeneous nucleation effect of fillers in PPGC composites, the overall crystallization rate has been enhanced which shows lower $\Delta E$ values. The dispersion of $5 \mathrm{wt} \%$ of MWCNTs reduces the crystallization rate due to the large number of nucleation sites and in turn restricts PP macromolecular mobility in composites.

\subsection{Nucleation activity}

The plots of $\ln R v s .1 / \Delta T_{\mathrm{p}}{ }^{2}$ for PP and PP composites are shown in Fig. S5. $\dagger$ It could be observed that slight deviation in linearity occurs. The parameter ' $B$ ' and ' $B$ ', could be estimated from the slopes of linear portion of these plots. The ' $B$ ' value is the slope obtained from the plot for PPG composite. The parameter ' $B$ ' obtained from the experimental results for PPG, PPGC1, PPGC2, PPGC3 and PPGC5 composites are respectively 0.540, 0.517, $0.394,0.506$ and 0.502 and the activity could be determined using expression $\phi=\frac{B^{*}}{B}$. The effect of nucleating activity with varying MWCNT content in PPGC composites is presented in Fig. 6. The microcomposite PPG is considered as the as the base matrix in this case and the activity is estimated for MWCNT's varying from 1 to $5 \mathrm{wt} \%$.

It was found that the activity values are lower for the PPGC composites containing $2 \mathrm{wt} \%$ MWCNTs. It is evident that an increase in MWCNT content causes an increase in the formation of PP crystal sites. This is further substantiated with lower value of ' $\phi$ ' suggesting that MWCNTs exhibit good nucleation properties in PP. Similar trend in nucleation activity was observed in the study involving $\mathrm{PP} /$ lignin $/ \mathrm{SiO}_{2}$ composites. ${ }^{15}$ Nevertheless, the nucleation activity does not increase at higher concentration of MWCNTs. The strongest nucleation activity was observed at an optimum MWCNT content of $2 \mathrm{wt} \%$. The inclusion of MWCNTs up to an optimum level in the micro composite system would have reduced the work required for arrangement of polymer chains and reduced size of crystals. Palza et al. ${ }^{33}$ also reported that the addition of low amount of nano filler increased the nucleation density and spherulites growth to a great extent.

\subsection{X-ray diffraction analysis}

It is well known that PP can crystallize in monoclinic ( $\alpha$ form), trigonal ( $\beta$ form) and triclinic ( $\Upsilon$ form). The influence of crystallization conditions strongly affects the diffraction reflexes. In the diffraction spectra of PP, the ' $\alpha$ ' peaks appear at $14.2^{\circ}, 17.1^{\circ}$, $18.5^{\circ}, 21^{\circ}$ and $22^{\circ}$ corresponding to (1 110$),\left(\begin{array}{lll}0 & 4 & 0\end{array}\right),\left(\begin{array}{lll}1 & 3 & 0\end{array}\right),(111)$ and $\left(\begin{array}{lll}1 & 3 & 1\end{array}\right)$ and $\left(\begin{array}{lll}0 & 4 & 1\end{array}\right)$ lattice planes. Normally the $\beta$-crystal peaks appear at $16^{\circ}\left(\begin{array}{lll}3 & 0 & 0\end{array}\right), 21^{\circ}\left(\begin{array}{lll}3 & 0 & 1\end{array}\right)$ and $r$ peaks at $20.05^{\circ}\left(\begin{array}{ll}1 & 1\end{array}\right.$ 7) respectively. ${ }^{34}$

The $d$ spacing between atomic planes of ' $\alpha$ ' form crystals $\left(d_{h k l}\right)$ could be estimated using the Braggs eqn (14)..$^{35}$

$$
n \lambda=2 d_{h k l} \sin \theta_{h k l}
$$


(a)

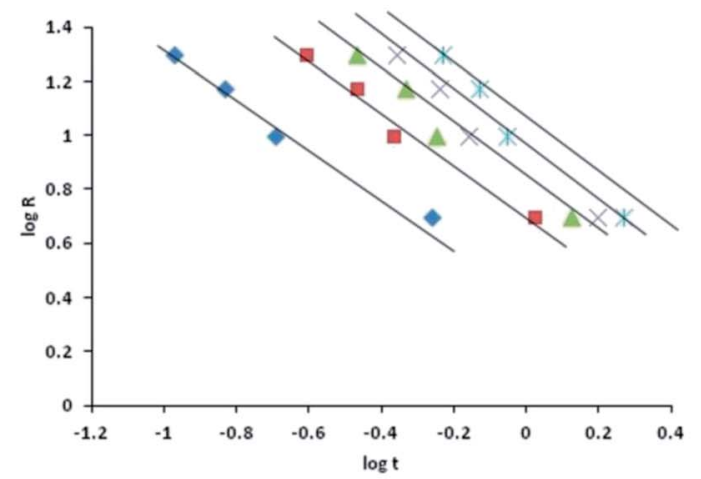

(c)

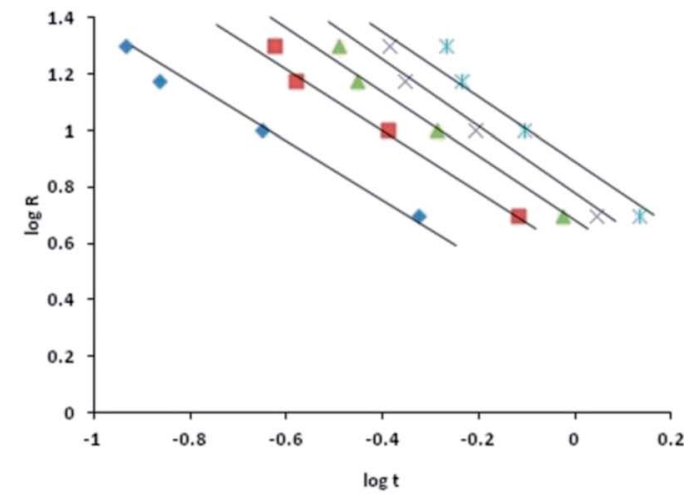

(e)

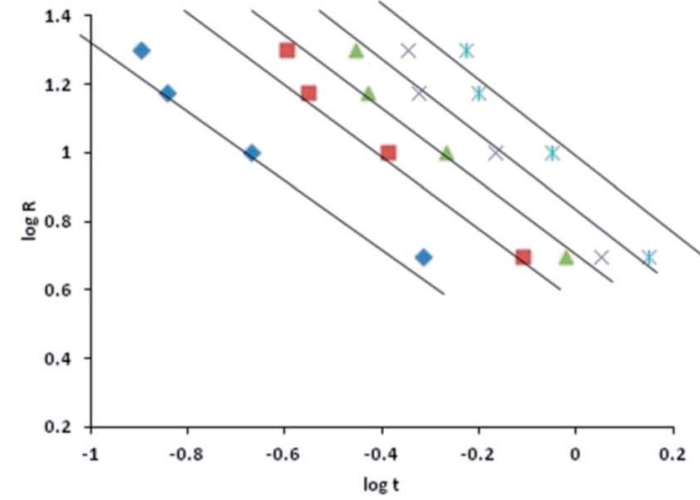

(b)

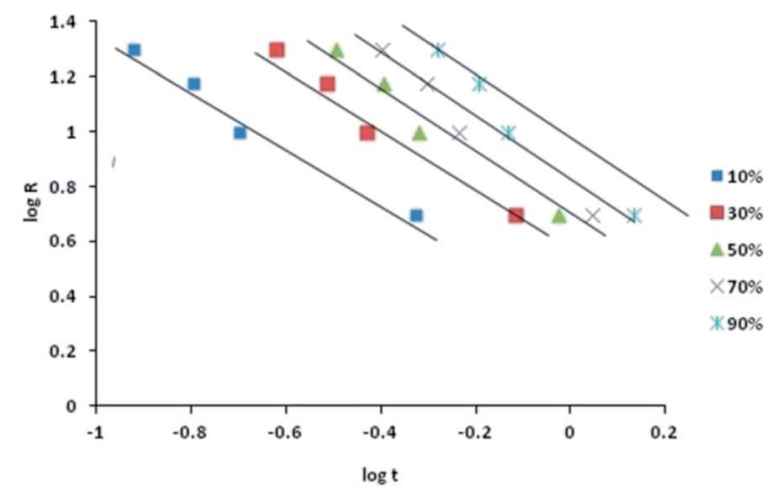

(d)

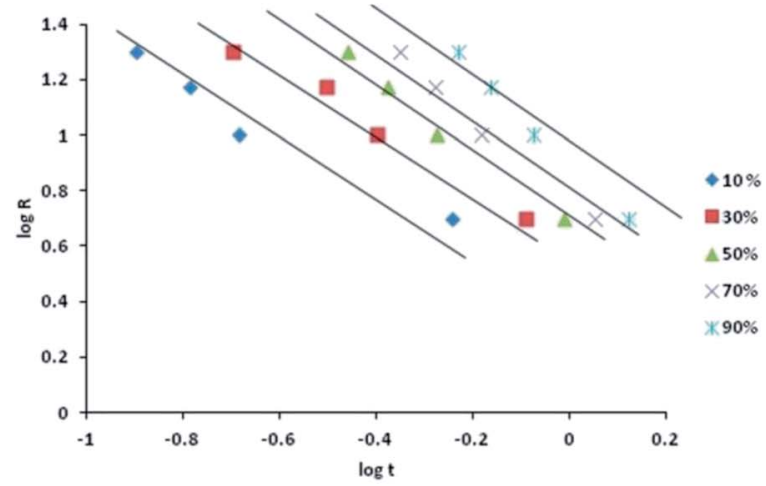

(f)

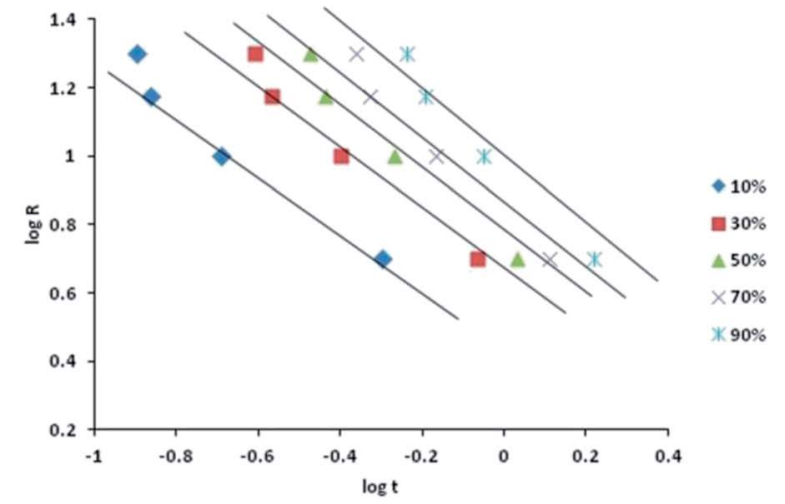

Fig. 5 Mo plots of $\log R$ versus log $t$ for varying percent relative crystallinity for non isothermal crystallization (a) PP, (b) PPG, (c) PPGC1, (d) PPGC2, (e) PPGC3, (f) PPGC5.

where ' $n$ ' is the order of diffraction, ' $\lambda$ ' is the wavelength of incident X-ray radiation, $h k l$ represents miller indices of the crystal planes and $\theta_{h k l}$ being the Bragg's angle. The size of the crystallites $\left(L_{h k l}\right)$ in a direction perpendicular to the lattice planes can be calculated using Debye-Scherer eqn (15). ${ }^{35}$

$$
L_{h k l}=\frac{k \lambda}{\beta_{h k l} \cos \theta_{h k l}}
$$

where Scherer constant ' $k$ ' is dependent on shape, size and distribution of crystallites (shape factor $k$, is assumed to be 0.9 in this study), $\beta_{h k l}$ is the full width at half maxima obtained from the peaks at respective $2 \theta$ angles.
As shown in Fig. 7, the peaks observed for PPG micro composite are of very low intensity and sharpness. The broader peaks refer to the smaller size of the crystallites grown at the respective ' $\alpha$ ' planes. The crystallite size $L_{h k l}$ obtained for the different diffraction peaks were $9.9 \mathrm{~nm}, 12.1 \mathrm{~nm}, 8 \mathrm{~nm}, 5.6 \mathrm{~nm}$ and $1.5 \mathrm{~nm}$ corresponding to $14.2^{\circ}, 16.9^{\circ}, 18.6^{\circ}, 21.6^{\circ}$ and $25.8^{\circ}$ respectively. Interestingly, the addition of $1 \mathrm{wt} \%$ of CNT in PPG micro composite significantly enhanced the intensity and sharpness of the peaks whereas the inclusion of 2 and $3 \mathrm{wt} \%$ of CNT reduced their intensity and broadened them. The appreciable increment in peak intensity of PPGC1 compared to other 


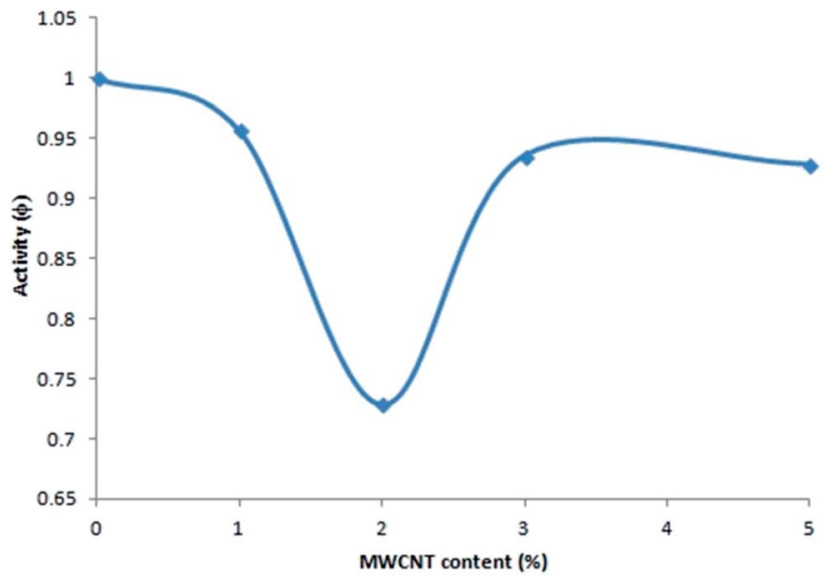

Fig. 6 Variation of nucleation activity with MWCNT content in PP/ glass fibre composites.

PPGC composites could be indicative of the growth of large crystallites. The sharpness of the peak intensity for PPGC1 suggests the large number of crystallites oriented in the atomic planes corresponding to $14.2^{\circ}, 17^{\circ}, 18.7^{\circ}$. Furthermore, PPGC2 exhibits sharper peaks relative to PPGC3 and PPGC5 composites. PPGC2 yielded smaller crystallites as calculated by DebyeScherer equation. The average crystal sizes of PPGC2 were $9.8 \mathrm{~nm}, 5.1 \mathrm{~nm}, 8.3 \mathrm{~nm}$ and $2.6 \mathrm{~nm}$ for the planes at $18.8^{\circ}, 21.9^{\circ}$, $25.6^{\circ}$ and $28.6^{\circ}$, respectively. The crystal sizes obtained for PPGC3 were slightly higher than those of PPGC2. At an higher loading of $5 \mathrm{wt} \%$ of MWCNT s (PPGC5) the sharpness and the intensity of peaks increased slightly in comparison with PPGC2 and PPGC3. Furthermore, crystal sizes for PPGC5 increased dramatically at all $\alpha$ planes which could be attributed to the formation of coarse structured crystals. As the composition of nano filler increases, agglomerates are generated and effective number of nucleating sites decreases leading to the formation of large and coarse crystallites.

\section{Conclusions}

From this study of non-isothermal crystallization kinetics of PP reinforced with glass fibre and MWCNTs yielded the following conclusions.

- The peak crystallization temperatures of PP phase in the composites are higher than that of neat PP at all cooling rates. The crystallization rate of PP increases with incorporation of fillers at all cooling rates as detected from the reduction in the half time for crystallization $\left(t_{1 / 2}\right)$. It was found that the nucleating effect is pronounced when the content of MWCNTs reaches $2 \mathrm{wt} \%$.

- The crystallization kinetics of the composite samples was analyzed using Avrami, Ozawa and Mo's models. It was observed that as the cooling rate increases, the $Z_{\mathrm{c}}$ values rises. At the same cooling rate, $Z_{\mathrm{c}}$ of PPG and PPGC composites were higher than $Z_{\mathrm{c}}$ of neat PP. According to Avrami model the experimental results obtained at the initial stages of crystallization correctly explains the non-isothermal crystallization behavior but deviates significantly at the later stages. Ozawa model resulted to be not suitable to explain the non-isothermal crystallization kinetics of the present system. In fact, the nonlinearity obtained in the Ozawa plots makes it difficult to apply in crystallization studies of PPGC composites.

- Mo's model resulted to be capable to efficiently model the non-isothermal crystallization kinetics of neat PP and relative composites. The lower values of $F(T)$ and perfect linearity of the plots enable the Mo's model to explain the synergistic effect of MWCNTs and glass fibre on the crystallization of PP.

- The nucleation effect of PPGC composite with MWCNT content of $2 \mathrm{wt} \%$ (PPGC2) exhibited the maximum work

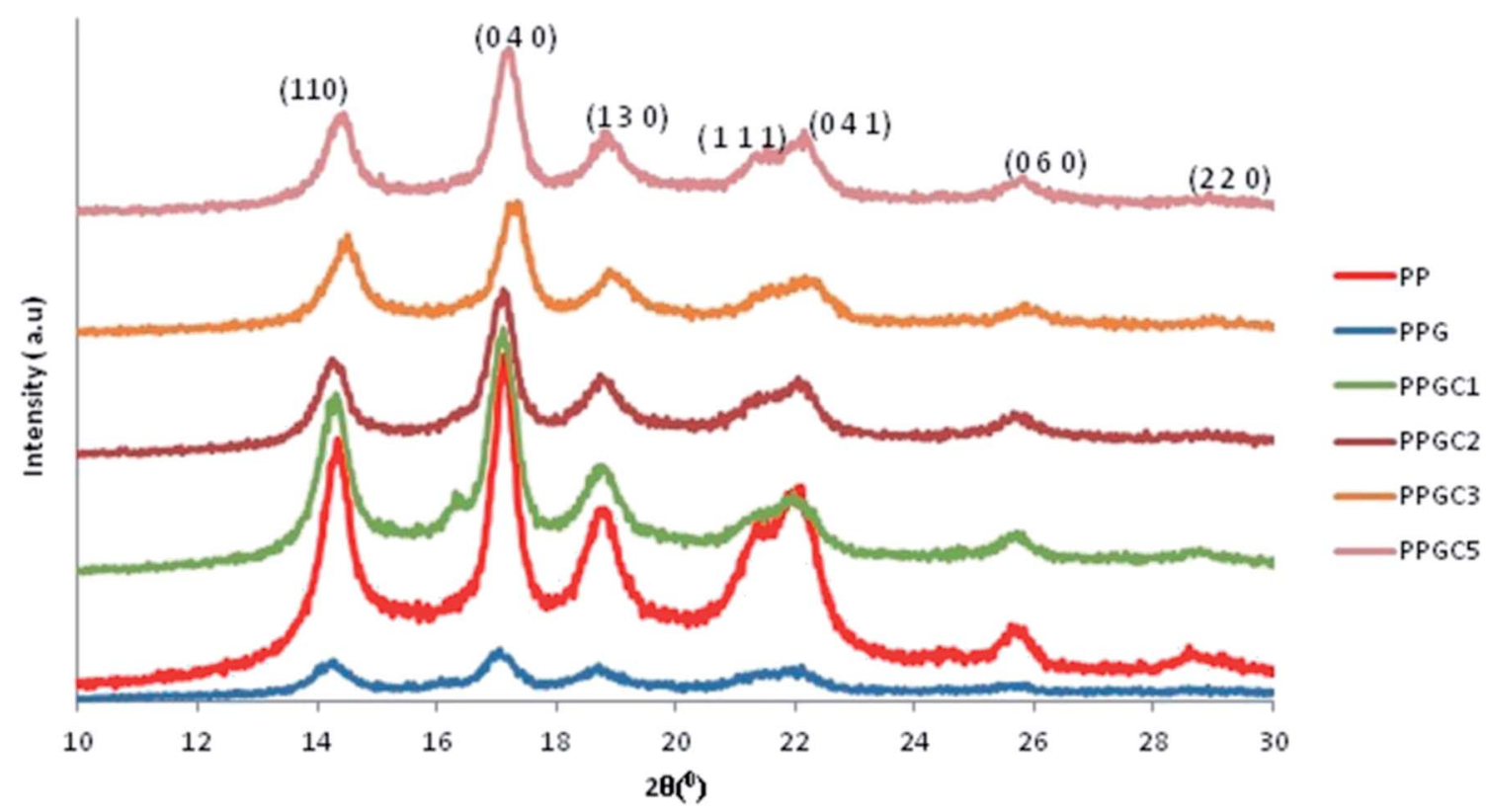

Fig. 7 X-ray diffraction patterns of neat PP, PPG and PPGC composites. 
decrement of $27 \%$ in comparison with PPG composite. The results of effective energy barrier of crystallization $(\Delta E)$ revealed the influence of fillers on the mobility of PP chains. The lowest activation energy was obtained for PPGC2 composite and it increased both above and below that concentration of MWCNT. The nucleating activity value was the lowest for PPGC2 making it the optimum amongst the PPGC composites in enhancing the crystallization of PP.

- XRD analysis demonstrated no significant shift of diffraction reflexes which indicated that PP crystal lattice planes were not changed with the inclusion of multiscale fillers. The incorporation of filler content increased the number of nucleating sites and reduced the crystallite sizes. Beyond $5 \mathrm{wt} \%$ of MWCNT larger size crystallites were formed.

\section{Conflicts of interest}

There are no conflicts to declare.

\section{Acknowledgements}

The authors thank Sophisticated Testing and Instrumentation Centre (STIC), Kochi, India and PSG Tech, Coimbatore, India for TEM and SEM analysis. The authors are grateful to Center of Excellence in Advanced Materials and Green Technologies (CoE-AMGT), Amrita School of Engineering, Coimbatore, Amrita Vishwa Vidyapeetham, India for DSC analysis.

\section{References}

1 C. Valerio-Cárdenas, A. Romo-Uribe, R. Cruz-Silva, L. Rejon and R. Saldivar-Guerrero, Isothermal crystallization of novel polypropylene/polyaniline-grafted-short glass fibre (Pan-g-SGF)composites, Emerging Mater. Res., 2012, 1(1), 39-48.

2 A. Layachi, D. Frihi, H. Satha, R. Seguela and S. Gherib, Nonisothermal crystallization kinetics of polyamide 66/glass fibres/carbon black composites, J. Therm. Anal. Calorim., 2016, 3(124), 1319-1329.

3 W. Hao, W. Yang, H. Cai and Y. Huang, Non-isothermal crystallization kinetics of polypropylene/silicon nitride nanocomposites, Polym. Test., 2010, 4(29), 527-533.

4 E. Assouline, A. Lustiger, A. H. Barber, C. A. Cooper, E. Klein, E. Wachtel and H. D. Wagner, Nucleation ability of multiwall carbon nanotubes in polypropylene composites, J. Polym. Sci., Part B: Polym. Phys., 2003, 5(41), 520-527.

5 M. K. Seo, J. R. Lee and S. J. Park, Crystallization kinetics and interfacial behaviors of polypropylene composites reinforced with multi-walled carbon nanotubes, Mater. Sci. Eng., A, 2005, 1(404), 79-84.

6 C. Marco, M. Naffakh, M. A. Gómez, G. Santoro and G. Ellis, The crystallization of polypropylene in multiwall carbon nanotube-based composites, Polym. Compos., 2011, 2(32), 324-333.

7 S. Nagae, Y. Otsuka, M. Nishida, T. Shimizu, T. Takeda and S. Yumitori, Transcrystallization at glass fibre/ polypropylene interface and its effect on the improvement of mechanical properties of the composites, J. Mater. Sci. Lett., 1995, 17(14), 1234-1236.

8 N. Pengfei, W. Xiaojun, L. Baoying, L. Shengru and Y. Jie, Melting and nonisothermal crystallization behavior of polypropylene/hemp fibre composites, J. Compos. Mater., 2012, 2(46), 203-210.

9 C. S. Park, K. J. Lee, J. D. Nam and S. W. Kim, Crystallization kinetics of glass fibre reinforced PBT composites, J. Appl. Polym. Sci., 2000, 3(78), 576-585.

10 Y. Peneva, M. Valcheva, L. Minkova, M. Mičušík and M. Omastová, Nonisothermal Crystallization Kinetics and Microhardness of PP/CNT Composites, J. Macromol. Sci., Part B: Phys., 2008, 47, 1197-1210.

11 N. Oburoğlu, N. Ercan, A. Durmus and A. Kașgöz, Effects of Halloysite Nanotube on the Mechanical Properties and Nonisothermal Crystallization Kinetics of Poly(Butylene Terephthalate) (PBT), J. Macromol. Sci., Part B: Phys., 2012, 51, 860-879.

12 W. Hao, X. Wang, W. Yang and K. Zheng, Non-isothermal crystallization kinetics of recycled $\mathrm{PET}^{-\mathrm{Si}_{3} \mathrm{~N}_{4}}$ nanocomposites, Polym. Test., 2012, 1(31), 110-116.

13 H. Xiong, Y. Gao and H. Li, Non-isothermal crystallization kinetics of syndiotactic polystyrene-polystyrene functionalized SWNTs nanocomposites, eXPRESS Polym. Lett., 2007, 1, 416.

14 M. Sattari, S. A. Mirsalehi, A. Khavandi, O. Alizadeh and M. R. Naimi-Jamal, Non-isothermal melting and crystallization behavior of UHMWPE/SCF $/$ nano-SiO $_{2}$ composites, J. Therm. Anal. Calorim., 2015, 3(122), 13191330 .

15 S. Borysiak, L. Klapiszewski, K. Bula and T. Jesionowski, Nucleation ability of advanced functional silica/lignin fillers in polypropylene composites, J. Therm. Anal. Calorim., 2016, 1(126), 251-262.

16 A. Dobreva and I. Gutzow, Activity of substrates in the catalyzed nucleation of glass-forming melts. I Theory, $J$. Non-Cryst. Solids, 1993, 1(162), 1-12.

17 A. Dobreva and I. Gutzow, Activity of substrates in the catalyzed nucleation of glass-forming melts. II Experimental evidence, J. Non-Cryst. Solids, 1993, 162, 13-25.

18 J. Qian, P. He and K. Nie, Nonisothermal crystallization of PP/nano-SiO ${ }_{2}$ composites, J. Appl. Polym. Sci., 2004, 2(91), 1013-1019.

19 N. Rasana and K. Jayanarayanan, Polypropylene/short glass fibre/nanosilica composites: evaluation of morphology, mechanical, thermal, and transport properties, Polym. Bull., 2018, 75(6), 2587-2605.

20 K. Jayanarayanan, S. S. Bhagawan, S. Thomas and K. Joseph, Morphology development and non isothermal crystallization behaviour of drawn blends and microfibrillar composites from PP and PET, Polym. Bull., 2008, 4(60), 525-532.

21 M. C. Kuo, J. C. Huang and M. Chen, Non-isothermal crystallization kinetic behavior of alumina nanoparticle filled poly(ether ether ketone), Mater. Chem. Phys., 2006, 2(99), 258-268. 
22 M. C. Kuo, J. S. Kuo, M. H. Yang and J. C. Huang, On the crystallization behavior of the nano-silica filled PEEK composites, Mater. Chem. Phys., 2010, 2(123), 471-480.

23 N. Rasana and K. Jayanarayanan, Experimental and micromechanical modeling of fracture toughness: MWCNT-reinforced polypropylene/glass fibre hybrid composites, J. Thermoplast. Compos. Mater., 2018, DOI: 10.1177/0892705718785687.

24 A. Bahader, H. Gui, Y. Li, P. Xu and Y. Ding, Crystallization kinetics of PVDF filled with multi wall carbon nanotubes modified by amphiphilic ionic liquid, Macromol. Res., 2015, 3(23), 273-283.

25 E. Basavaraj, B. Ramaraj and J. H. Lee, Microstructure, thermal, physico-mechanical and tribological characteristics of molybdenum disulphide-filled polyamide 66/carbon black composites, Polym. Eng. Sci., 2013, 8(53), 1676-1686.

$26 \mathrm{~W}$. Xu and M. GeP. He, Nonisothermal crystallization kinetics of polypropylene/montmorillonite nanocomposites, J. Polym. Sci., Part B: Polym. Phys., 2002, 5(40), 408-414.

27 T. Liu, Z. Mo and H. Zhang, Nonisothermal crystallization behavior of a novel poly(aryl ether ketone): PEDEKmK, $J$. Appl. Polym. Sci., 1998, 5(67), 815-821.

$28 \mathrm{~W}$. Weng, G. Chen and D. Wu, Crystallization kinetics and melting behaviors of nylon 6/foliated graphite nanocomposites, Polymer, 2003, 26(44), 8119-8132.
29 G. S. Deshmukh, D. R. Peshew, S. U. Pathak and J. D. Ekhe, Nonisothermal crystallization kinetics and melting behavior of poly(butylene terephthalate) (PBT) composites based on different types of functional fillers, Thermochim. Acta, 2014, 581(suppl. C), 41-53.

30 J. Shi, X. Yang, X. Wang and L. Lu, Non-isothermal crystallization kinetics of nylon 6/attapulgite nanocomposites, Polym. Test., 2010, 5(29), 596-602.

31 J. Li, Z. Fang, Y. Zhu, L. Tong, A. Gu and F. Liu, Isothermal crystallization kinetics and melting behavior of multiwalled carbon nanotubes/polyamide-6 composites, $J$. Appl. Polym. Sci., 2007, 6(105), 3531-3542.

32 S. S.anll, A. Durmus and N. Ercan, Isothermal crystallization kinetics of glass fibre and mineral-filled polyamide 6 composites, J. Mater. Sci., 2012, 7(47), 3052-3063.

33 H. Palza, J. Vera, M. Wilhelm and P. Zapata, Spherulite Growth Rate in Polypropylene/Silica Nanoparticle Composites: Effect of Particle Morphology and Compatibilizer, Macromol. Mater. Eng., 2011, 296, 744-751.

34 K. Jayanarayan, K. S. Thomas and K. Joseph K, In situ microfibrillar blends and composites of polypropylene and poly(ethylene terephthalate): morphology and thermal properties, J. Polym. Res., 2011, 1(18), 1-11.

35 A. B. Kaganj, A. M. Rashidi, R. Arasteh and S. Taghipoor, Crystallization behavior and morphological characteristics of poly(propylene)/multi-walled carbon nanotube nanocomposites, J. Exp. Nanosci., 2009, 4(22), 21-34. 